\title{
A Simple Way to Achieve Self-Cleaning Surfaces with Unique Antifouling Property
}

\author{
Caizhen Yao $\mathbb{D}^{1},{ }^{1}$ Shizhen Xu $\mathbb{D}^{1},{ }^{1,2}$ Xiaodong Jiang, ${ }^{1}$ Jiaxuan Chen, ${ }^{3}$ and Xiaodong Yuan ${ }^{1}{ }^{1}$ \\ ${ }^{1}$ Laser Fusion Research Center, CAEP, P.O. Box 919-988-5, Mianyang 621900, China \\ ${ }^{2}$ School of Physical Electronics, University of Electronic Science and Technology of China, Chengdu 610054, China \\ ${ }^{3}$ Harbin Institute of Technology, Harbin 150001, China \\ Correspondence should be addressed to Caizhen Yao; yaocaizhen2008@126.com and Xiaodong Yuan; yxd66my@163.com
}

Received 5 May 2020; Accepted 29 June 2020; Published 31 July 2020

Guest Editor: Zhen He

Copyright ( $\odot 2020$ Caizhen Yao et al. This is an open access article distributed under the Creative Commons Attribution License, which permits unrestricted use, distribution, and reproduction in any medium, provided the original work is properly cited.

Self-cleaning surfaces may have wide applications such as microfluidic devices, lab-on-a-chip, sensors, microreactors, air purification, and antimicrobial fields. In this article, by using a combination of femtosecond (fs) laser irradiation and fluorination technique, self-cleaning stainless steel surfaces with unique antifouling property were obtained. New insight is developed through a detailed analysis of the antifouling behavior of the self-cleaning surfaces. The surface free energy and its polar and disperse components were calculated by using the Owens-Wendt--Rabel-Kaelble (OWRK) method. X-ray photoelectron spectroscopy was employed to analyse the surface elemental compositions and functional groups. The antifouling property of the surface was recorded by using a high speed camera. Water sliding angles (SAs) were reduced by fluorination treatment, resulting in low adhesive superhydrophobic surfaces with the self-cleaning property. The influences of micro/nanostructures, fluorination, and their combination on the surface free energy were investigated. The interaction process between water droplets and pollutants (inorganic and organic particles) on the treated surface was explored. The antifouling property of an optimized specimen $\left(\mathrm{CA}=162^{\circ}\right.$ and $\left.\mathrm{SA}=1^{\circ}\right)$ was tested and compared with the untreated sample.

\section{Introduction}

Contaminants on surfaces may threaten the health of people and the quality of products. Cleaning methods, e.g., swiping, ultrasonic cleaning, illuminating, and water spraying have been used to maintain surface cleanliness, which consumes labor, energy, capital, and time. Recently, surface treatment with self-cleaning properties has generated worldwide interest $[1,2]$. These surfaces are of great importance not only for the fundamental research but also for various practical applications. Antifouling paints/coatings are normally applied to metallic surfaces by using electrospinning $[2,3]$, spraying [4], vapor deposition [5], or electrochemical deposition [6]. These paints/coatings have good self-cleaning property. However, their disadvantages of low adhesion, poor temperature resistance, and discoloration due to weathering or mechanical damaging severely limit their application in extreme conditions. Inspired by lotus leaf, self-cleaning property can be obtained by surface micro/ nanostructuring. Water droplets pick up dirt particles and debris from a tilt surface and roll-off to realize self-cleaning $[2,7]$. Metallic surfaces with self-cleaning property have huge potential applications in microfluidic devices, lab-ona-chip, sensors, microreactors, air purification, and antimicrobial fields [8]. For example, as the interior surfaces, the washing process for pipelines of milk or petroleum can be greatly simplified. The exterior surfaces would be cleaned by rain water without using detergent, saving the maintenance, and labor costs [2]. Furthermore, ships' body can be better protected due to the low adhesion of biological pollutants [9].

Femtosecond ( $\mathrm{fs}$ ) laser technique has proved to be a promising method to produce micro/nanostructures on surfaces for its unique abilities and advantages, including the following. (1) This is a maskless technique with $0-3$ dimensional micro/nanoscale structures being able to form 
simultaneously [10]. (2) It can be applied to a variety of materials such as polymers [11-15], metals [10, 16-19], and semiconductors [7] in various environments (e.g., air [7, 12-14, 16-18], gaseous atmosphere [20], vacuum, and liquid environments [10]). (3) Precise micro/nanostructure can be realized by controlling laser parameters and/or environments to fine-tune the surface wettability and adhesive property $[9,21]$. (4) It has minimum thermal effect so that the property of substrate can be preserved [22, 23]. Despite its infancy, the outstanding micro/nanostructure fabrication of femtosecond laser has been raised worldwide attention, including Wolter from Laser Zentrum Hannover e.V. [19], Jeon from KIST Korea [11], Guo from University of Rochester [24, 25], Hatzikiriakos from UBC Canada [16], Li from USTC China [10], Chen from Xi'an Jiaotong University $[7,13,15,26]$, and Zhong from Tsinghua University [17]. In his review article, Chen et al. [26] pointed out that laser microfabrication can realize special modulation ranging from superhydrophilic to superhydrophobic, allowing much more freedom to achieve complex multiplewettability integration. Zhang et al. [7] adopted femtosecond laser irradiation technique to achieve the tunable adhesive superhydrophobic silicon surfaces and revealed that the adhesive forces of as-prepared surfaces can be tuned by varying the area ratio of superhydrophobic domain to hydrophobic domain. Jun et al. [11] generated microscale grooves on nanofibrous platforms using a femtosecond laser ablation process to develop engineered fibrous platforms with patterned hierarchical topographies. The fabricated platforms can regulate cellular adhesive morphology, proliferation, and distinct distribution of focal adhesion proteins. By tailoring the surface chemical composition and surface morphology, Moradi et al. [16] reported the effect of extreme surface wettability on platelet adhesion and activation in SS and Ti surfaces. Li et al. [10] reported the assembly of self-organized 3-dimensional porous metal micro/ nanocages arrays on nickel surface by ethanol-assisted femtosecond laser irradiation. The underlying formation mechanism was also investigated. The 3D cage-like micro/ nanostructures exhibit not only improved antireflection property but also enhanced hydrophobicity. However, the interaction behaviour and mechanism between water droplets and pollutants on self-cleaning surfaces were seldom reported.

In this paper, superhydrophobic surfaces were obtained by using one-step femtosecond laser irradiation. Its surface free energy was greatly reduced by a fluorination process to achieve excellent self-cleaning property. Surface morphologies, surface functional groups, surface free energy, static wettability, and dynamic wettability were characterized. The interaction behavior between water droplets and pollutants on self-cleaning stainless steel (SS) was investigated. The self-cleaning mechanism was also explored. This paper aims to bridge the gap between superhydrophobic surface and self-cleaning surface.

\section{Experimental Process}

2.1. Samples Preparation. Experiments were performed in a clean room at $23^{\circ} \mathrm{C}$ in ambient atmosphere. Mirror-like 304
SS coupons with a dimension of $20 \mathrm{~mm} \times 20 \mathrm{~mm} \times 2 \mathrm{~mm}$ were used as substrates. The schematic of experimental setting up can be referred to a previous study [27]. In brief, a commercial Ti:sapphire chirped-pulse amplification laser system (Spectra Physics) was used to generate a 35 fs horizontally linear polarized laser with a central wavelength of $800 \mathrm{~nm}$. The beam has a Gaussian profile. A neutral density (ND) attenuator was used to adjust the pulse energy. Femtosecond laser pulses were focused to $e^{-2}$ spot diameter of $300 \mu \mathrm{m}$ by using a $150 \mathrm{~mm}$ focal length lens. Substrates were mounted perpendicular to the laser beam on a precision computer-controlled 3D translation stage. The laser repetition rate is $1 \mathrm{kHz}$. The pulse number per spot was controlled by the combination of an electric shutter and the speed of translation stage. Laser scan irradiation mode was employed to get large and uniform surface areas for antifouling property tests.

In order to evaluate the surface morphologies of samples over a range of experimental parameters, the influence of fluence $\left(F=0.3,0.5,0.7,1.0,1.3,1.5,1.6,1.9,2.0 \mathrm{~J} / \mathrm{cm}^{2}\right.$, respectively) and pulse number per focal spot (PPS $=10,20$, $30,100,200,300$ pulses, respectively) were systematically investigated. After laser treatment, the fluorination process was performed to reduce surface free energy. Samples were cleaned by ultrasonic cleaning in water at $23^{\circ} \mathrm{C}$ for $10 \mathrm{~min}$ and then immersed into $1 \%$ fluoroalkylsilane $\left(\mathrm{C}_{14} \mathrm{H}_{19} \mathrm{~F}_{13} \mathrm{O}_{3} \mathrm{Si}\right)$ solution for $30 \mathrm{~min}$. The samples were immediately treated in a furnace at $135^{\circ} \mathrm{C}$ for $30 \mathrm{~min}$. Mirror-like 304 SS coupons were fluorinated with the same procedure and tested for comparison purpose.

2.2. Characterization. Images of surface morphologies and microstructures were obtained by using a Phenom scanning electron microscope (SEM) with an accelerating voltage of $10 \mathrm{kV}$. Samples were sputter-coated with a $5 \mathrm{~nm}$ gold layer before observation. Contact angles (CAs) and surface free energy were characterized by using interface tension meter (Kruss K100). Owens-Wendt-Rabel-Kaelble (OWRK) method was employed to calculate surface free energy and its polar and disperse components. The disparity between water and hexadecane in the appearance of CA was due to the difference of surface tension. Hexadecane has a lower surface tension of $\gamma \mathrm{HD}=26.7 \mathrm{mN} / \mathrm{m}$ in comparison with that of water $\gamma \mathrm{H}_{2} \mathrm{O}=72.0 \mathrm{mN} / \mathrm{m}$. X-ray photoelectron spectroscopy (XPS) was used to test the surface elemental compositions and functional groups of specimens before and after fluorination. $\mathrm{Al} \mathrm{K} \alpha$ was used as X-ray source. A step-scan mode was used at the binding energy ranging from 0 to $1360 \mathrm{eV}$ with an energy step size $1 \mathrm{eV}$. Water bouncing and rolling behaviors on specimens were recorded by using a high speed camera (Pro.1200 hs). The interaction between water droplets and pollutants on self-cleaning SS was also monitored.

\section{Results and Discussion}

3.1. Surface Morphology and Microstructure. Systematic investigation of femtosecond laser-induced micro/nanostructures 
on 304SS was performed and a F-PPS model was built, which can be used to locate and fine-tune the laser settings to produce a specific surface microstructure in laser scan irradiation mode. As shown in Figure 1, two types of micro/nanostructures were observed: the laser-induced periodic surface structures (LIPSSs) on $S 1, S 2, S 3$, and $S 4$, and nodular structures on $S 5$ and $S 6$. LIPSSs on 304SS are located at $F$ lower than $1 \mathrm{~J} / \mathrm{cm}^{2}$. With increasing $F$, the nodular structures start to form. The two types of structures have different formation mechanism and different structure properties. This result is consistent with literatures $[3,11,28]$, indicating that, at low fluences $\left(<1 \mathrm{~J} / \mathrm{cm}^{2}\right)$, the ablation process is dominated by the optical penetration depth and, at high fluences $\left(\geq 1 \mathrm{~J} / \mathrm{cm}^{2}\right)$, the electron heat diffusion length is the domination parameter. Interestingly, with increasing PPS from 5 pulses to 300 pulses at the same $F$, the structure types were kept almost the same. However, the dimensions of nodular structures increased dramatically, which may be due to the incubation effect $[27,29,30]$. Thus, in this F-PPS model, $F$ determines the type of structures and PPS determines the dimensions of structures. This result is consistent with the numerical simulation results of Zhang et al. [31], who demonstrate that, according to the two-temperature model for multipulse laser irradiation, the lattice temperature will be much less affected if the time interval between two pulses is larger than the electron-lattice coupling time.

3.2. Surface Free Energy and Wettability Test. Surface free energy of a material is normally influenced by surface morphology and chemical composition. Their combined effects have been studied extensively. However, their respective influence on surface free energy and wettability of a material was seldom investigated, which is of great importance for the self-cleaning surface.

Table 1 and Figure 2 show the relations of surface free energies and CAs of specimens after femtosecond laser irradiation. The surface free energies vary significantly from $23.09 \pm 0.44 \mathrm{mN} / \mathrm{m}$ to $60.12 \pm 0.17 \mathrm{mN} / \mathrm{m}$ in comparison to the original $304 \mathrm{SS}(42.22 \pm 1.98 \mathrm{mN} / \mathrm{m})$. Tested surface free energy of $S 1$ and $S 2$ is lower than that of original 304SS, and it grows with increasing accumulated energy density. The water contact angle is slightly decreased with the increasing of surface free energy. $S 1$ has a CA of about $152^{\circ}$, showing superhydrophobicity. $S 6$ has a CA of about $9^{\circ}$, showing hydrophilicity. Similar results were reported by Pfleging et al. [32] on nanosecond laser irradiated titanium alloy. Low surface energy and decreased wettability may reduce the interaction between the metal surface and contaminants.

Table 2 and Figure 3 show the surface free energies are significantly reduced and CAs are greatly increased after fluorination. The surface free energy of fluorinated S1-S6 is much lower than that of $304 \mathrm{SS}(17.47 \mathrm{mN} / \mathrm{m})$ with the same fluorination process. All specimens show near superhydrophobic property $\left(\sim 150^{\circ}\right)$ while fluorinated 304SS has $\mathrm{CA}=103^{\circ}$. It can be concluded that proper micro/nanostructure fabrication and fluorination can be used to reduce surface free energy, and different micro/nanostructures have different fluorination effects.
According to the OWRK method, surface free energy is composed of disperse and polar components. Thus, a detailed analysis is performed on SS, S1, and S6 and their fluorinated samples FS, FS1, and FS6, to further understand the influence of fluorination on the free energy components. As shown in Table 3 and Figure 4, the values of polar component $(P)$ and disperse component $(D)$ of the three samples before fluorination follow the order of $P_{S 1}<P_{S S}<P_{S 6}$ and $D_{S 1}<D_{S S}<D_{S 6}$. $P_{S 1}$ and $D_{S 1}$ are significantly lower than those of original 304SS and S6. After fluorination, the polar component and disperse component of these samples were greatly reduced. Both $P_{\mathrm{FS} 1}$ and $P_{\mathrm{FS} 6}$ are so small that can be ignored in comparison with $\mathrm{P}_{\mathrm{FS}}$.

Polar component has significant effect on wettability. Polar molecules can enhance the wettability by interaction with dipole force and hydrogen bonds [32]. Thus, before fluorination, the water contact angle of untreated 304SS is smaller than that of $S 1$ and lager than that of $S 6$. $S 1$ shows superhydrophobicity due to the reduction of polar component. After fluorination, FS1 and FS6 show superhydrophobicity due to the elimination of polar component. FS6 has a lower surface free energy in comparison with FS1, which may be due to its large specific surface area. The deposition of more hydrophobic functional groups during the fluorination process can reduce the surface free energy of FS6. The relatively large polar component on FS can be used to explain why the fluorinated untreated 304SS surface does not have superhydrophobicity.

\subsection{Surface Functional Groups and Adhesive Property.} The dynamic wettability of original 304SS, superhydrophobic S1, and hydrophilic S6 samples was investigated by using high speed camera in Figure 5. A water droplet of $8 \mu \mathrm{l}$ fell from the same height above the tested surface. $S 1$ shows the absolute water repelling property, and S6 shows much higher wettability in comparison with the original 304SS due to the different types and dimensions of micro/nanostructures as shown in Figure 1.

$S 1$ has a CA of $152^{\circ}$; however, it shows adhesive property (Figure 6(a)), which is unfavorable for the formation of selfcleaning surface. A self-cleaning surface should have a high water repelling property and a low adhesive property to contribute the water droplet rolling process [33]. After treated by a fluorination process, the adhesive force is greatly reduced as shown in Figure 6(b). XPS analysis of $S 1$ in Figure 7 and Table 4 indicates that this may be related to the formation of hydrophobic functional groups, e.g., -C-F, $-\mathrm{C}-\mathrm{F}_{2}$, and $-\mathrm{C}-\mathrm{F}_{3}$. The peak position of $\mathrm{F}_{1 \mathrm{~s}}$ locates at $688.9 \mathrm{eV}$. The atomic percent of $-\mathrm{C}-\mathrm{F}_{2}$ increases to $26.94 \%$ after fluorination. During the fluorination process, metallic bonds and $-\mathrm{OH}$ will be replaced by hydrophobic groups. Hydrophobic groups have less adhesive force to water droplets, which contribute to the self-cleaning property.

3.4. Wettability Models. Figure 8 shows the wettability model of SS, S1, and $S 6$ before and after fluorination. It has been reported that micro/nanobinary structures on solid surfaces can effectively enhance hydrophobicity of the 

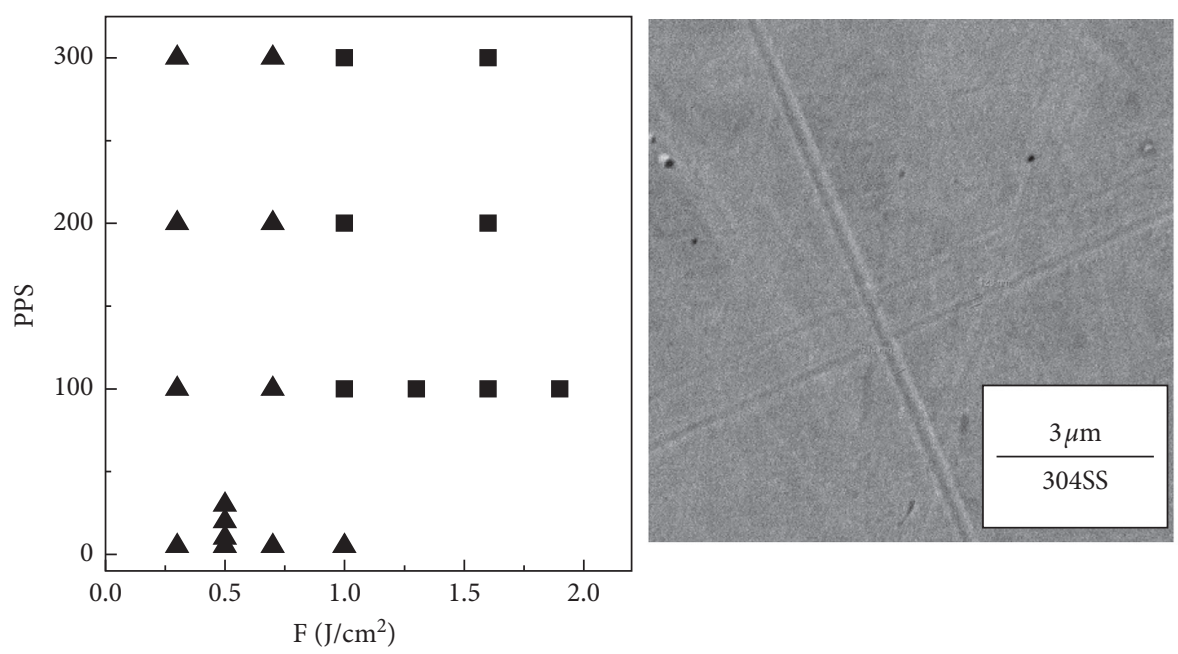

A LIPSSs

- Nodular structures
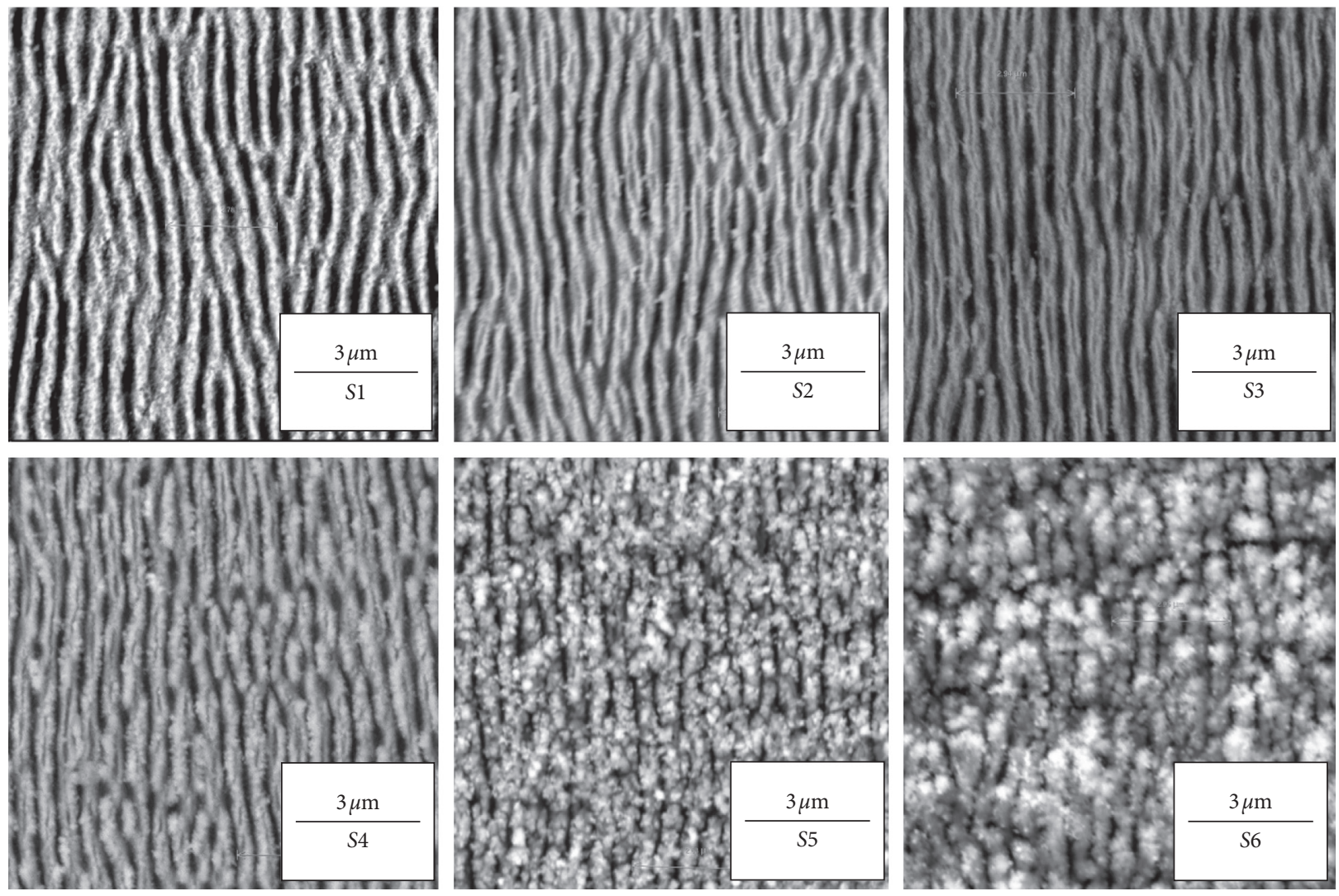

Figure 1: The influence of F and PPS on the evolution of surface morphology. PPS refers to the pulse number per focal spot and F refers to the pulse fluence. $S 1-S 3$ have the same $F=0.5 \mathrm{~J} / \mathrm{cm} 2$ with increasing PPS $=5,10$, and 20 pulses, respectively, and $S 4-S 6$ have the same PPS $=100$ pulses with increasing $F=0.5,1.5$, and $2.0 \mathrm{~J} / \mathrm{cm} 2$, respectively. Surface morphology of $304 S S$ is also given for comparison purpose.

TABLE 1: Surface free energies and CAs of specimens after laser irradiation.

\begin{tabular}{lcccc}
\hline Samples & Surface free energy $(\mathrm{mN} / \mathrm{m})$ & Standard deviation & Water contact angle $\left(^{\circ}\right)$ & Standard deviation \\
\hline 304SS & 42.22 & 1.98 & 83 & 0.41 \\
S1 & 23.09 & 0.44 & 152 & 0.76 \\
S2 & 33.20 & 0.17 & 145 & 0.72 \\
S3 & 45.02 & 0.57 & 138 & 0.69 \\
S4 & 50.00 & 0.50 & 11 & 0.69 \\
S5 & 59.56 & 0.21 & 9 & 0.05 \\
S6 & 60.12 & 0.17 & 0.04 \\
\hline
\end{tabular}




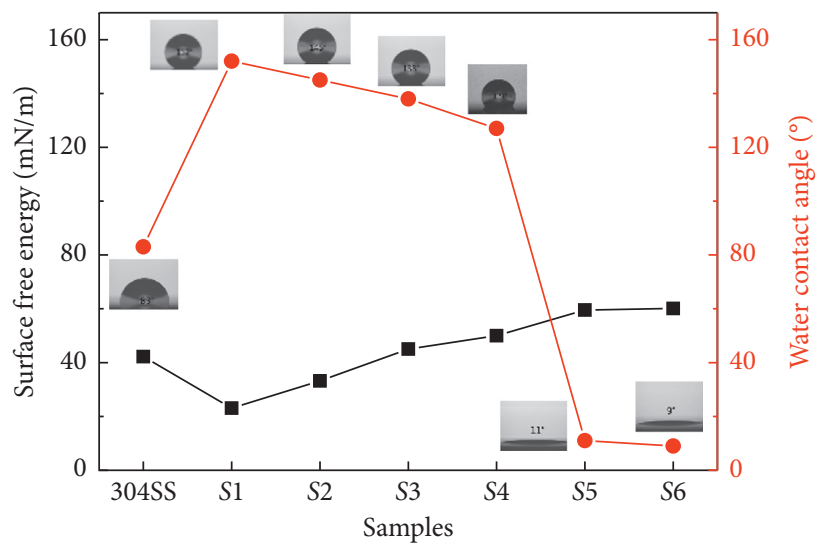

Figure 2: Comparison of surface free energies and water contact angles of specimens after femtosecond laser irradiation.

TABLE 2: Surface free energies and CAs of laser-treated specimens after fluorination.

\begin{tabular}{lcccc}
\hline Samples & Surface free energy $(\mathrm{mN} / \mathrm{m})$ & Standard deviation & Water contact angle $\left(^{\circ}\right)$ & Standard deviation \\
\hline S04SS & 17.47 & 1.29 & 103 & 0.55 \\
S1 & 5.15 & 0.09 & 162 & 0.81 \\
S2 & 3.13 & 0.16 & 160 & 0.80 \\
S3 & 1.96 & 0.42 & 144 & 0.72 \\
S4 & 2.55 & 0.14 & 146 & 0.75 \\
S5 & 0.94 & 0.05 & 150 & 0.73 \\
S6 & 2.37 & 0.23 & 0.75 \\
\hline
\end{tabular}

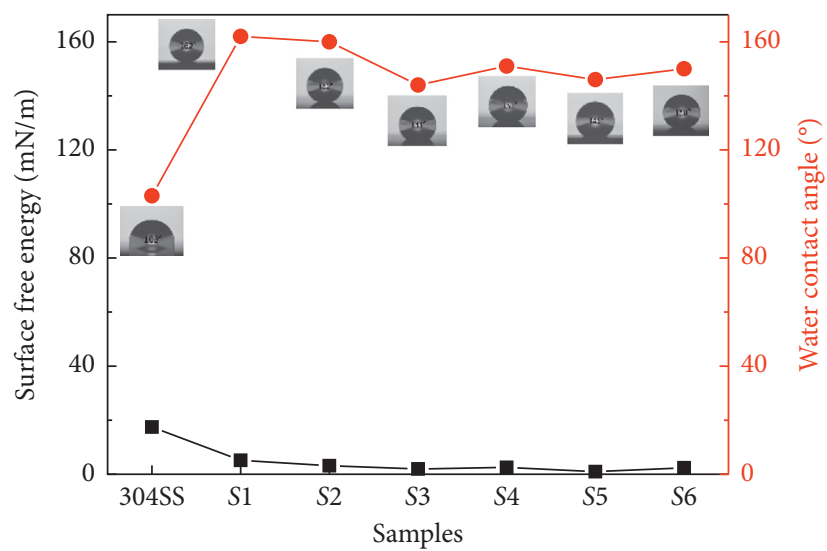

FIgURE 3: Surface free energies and CAs of laser-treated specimens after fluorination.

TABLE 3: Surface free energy and disperse and polar values before and after fluorination.

\begin{tabular}{lccc}
\hline Samples & Surface free energy $(\mathrm{mN} / \mathrm{m})$ & Disperse components $(\mathrm{mN} / \mathrm{m})$ & Polar components $(\mathrm{mN} / \mathrm{m})$ \\
\hline SS & $42.22 \pm 1.98$ & $31.40 \pm 0.28$ & $10.82 \pm 1.70$ \\
FS & $17.47 \pm 1.29$ & $13.85 \pm 0.46$ & $3.62 \pm 0.84$ \\
S1 & $23.09 \pm 0.44$ & $20.58 \pm 0.36$ & $2.51 \pm 0.08$ \\
FS1 & $5.15 \pm 0.09$ & $5.00 \pm 0.08$ & $0.14 \pm 0.01$ \\
S6 & $60.12 \pm 0.17$ & $45.96 \pm 0.12$ & $14.17 \pm 0.05$ \\
FS6 & $2.37 \pm 0.23$ & $2.34 \pm 0.21$ & $0.03 \pm 0.02$ \\
\hline
\end{tabular}

SS: untreated stainless steel, FS: fluorinated SS, FS1: fluorinated S1, and FS6: fluorinated S6.

surfaces $[34,35]$, giving the corroboration for the difference of hydrophobicity between the polished 304SS and laser treated surfaces. SS has a CA less than $90^{\circ}$ due to the existence of hydrophilic metallic bonds or hydroxyl groups. As shown in Figure $8(\mathrm{~b})$, the superhydrophobicity of $S 1$ comes from its microstructures (Figure 1) and can be 


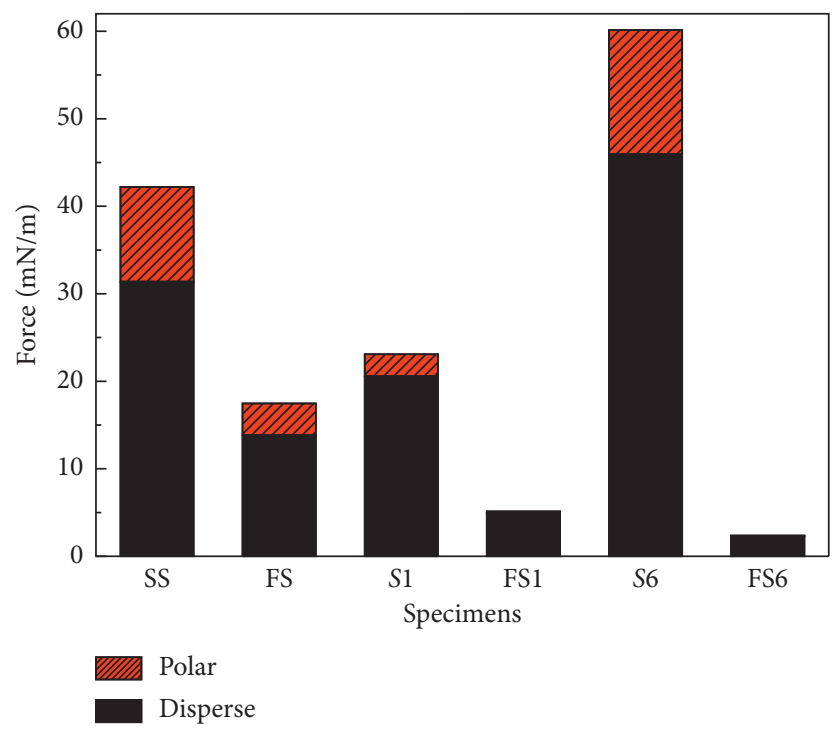

FIGURE 4: Disperse and polar components of surface free energy on specimens, showing both fluorination and micro/nanostructure are important for reducing surface free energy.
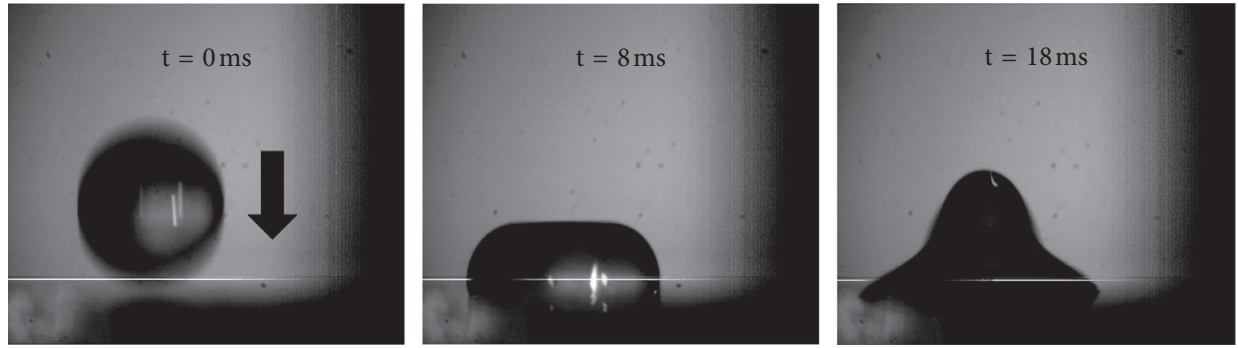

(a)
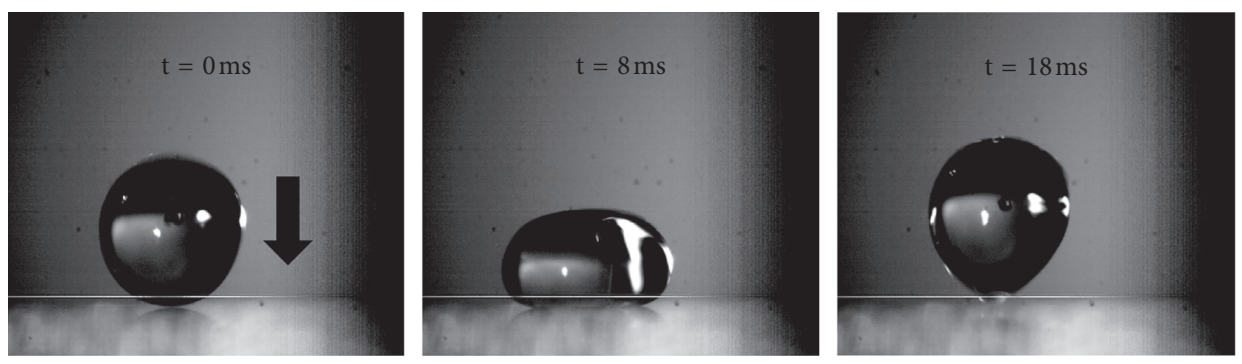

(b)
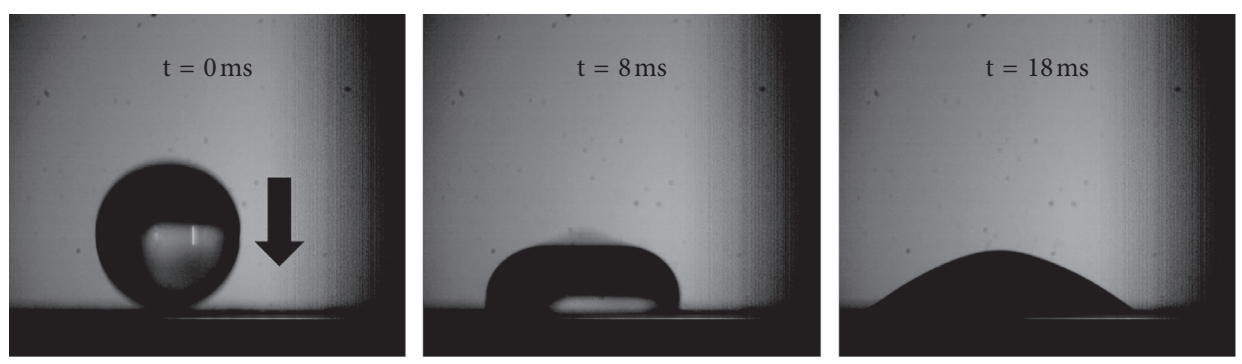

(c)
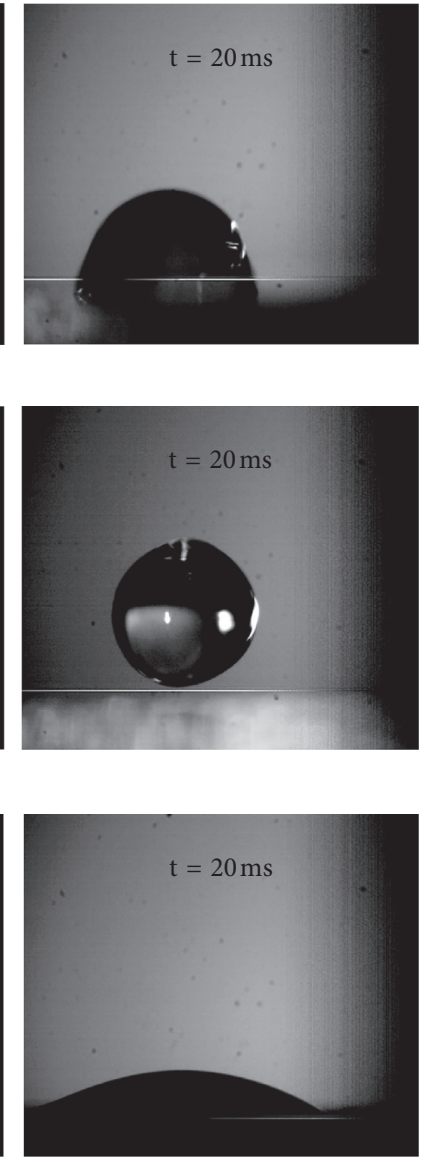

Figure 5: Dynamic behaviors of a falling water droplet on (a) original 304SS, (b) S1 with superhydrophobic property, and (c) S6 with hydrophilic property. 

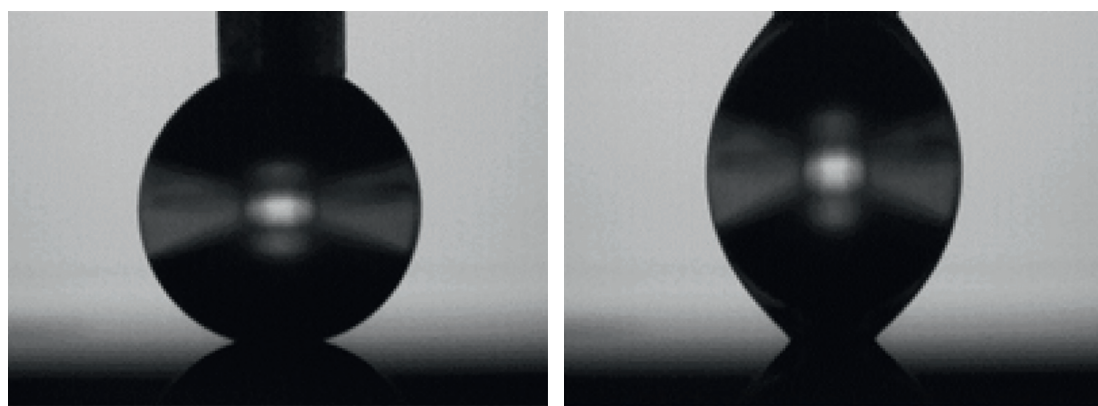

(a)
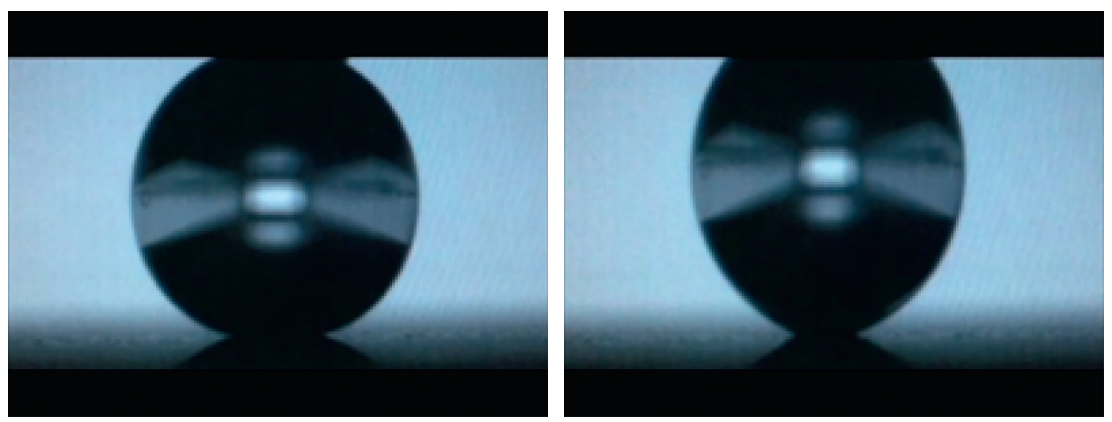

(b)
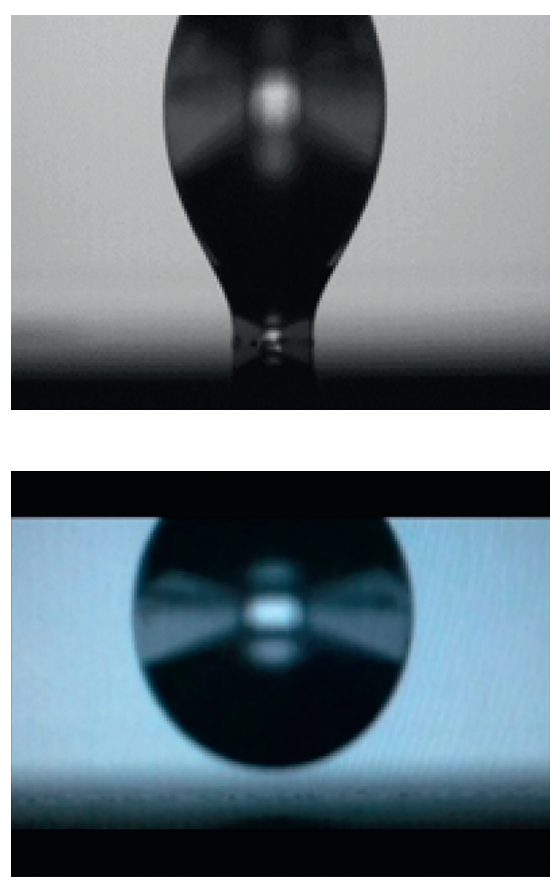

FIgURE 6: Adhesive property of S1: (a) before fluorination and (b) after fluorination.

explained by Cassie model [36]: when a water droplet is put on the surface of $S 1$, the droplet will only contact with the protuberance of the LIPSSs, covered by hydrophilic metallic bonds or hydroxyl groups. Meanwhile, air bubbles are trapped in the bottom, greatly reducing the contact area between the water droplet and sample. The hydrophilic property of S6 may be attributed to the growing of microstructures. In this case, the sample has a large surface area covered by hydrophilic metallic bonds or hydroxyl groups. Water will take the place of air and infiltrate into the microstructures as shown in Figure 8(c).

The three samples are further fluorinated as shown in Figures 8(d)-8(f). During the fluorination process, hydrophilic metallic bonds or hydroxyl groups are replaced by hydrophobic functional groups, which, combined with the trapped air bubbles, could be the reason for the excellent superhydrophobicity of FS1 and FS6. This result is consistent with literature [37]. The process of fluorination relies on the reaction of fluoroalkyl silane with - $\mathrm{OH}$ groups, leading to significant decrease in surface energy of sample. Moreover, heating in a furnace at $135^{\circ} \mathrm{C}$ may help to eliminate the surface hydroxyl groups, which could also be a reason for the hydrophilic-to-hydrophobic transition of samples.

3.5. Antifouling Modes. The interaction between water droplet and pollutant particle is crucial for the self-cleaning property. The most important adhesive forces between the pollutants and surface are the van der Waals' and electrostatic forces. The cleaning process requires a repelling force larger than the adhesive force. Thus, the surface free energy of a specimen must be controlled as small as possible. In this research, the interaction behaviors between water droplets and different types of particulate pollutants on self-cleaning SS were monitored and recorded. Three types of antifouling modes were built.

Figure $9(a)$ is a series of photos taken by using a high speed camera, showing the "rolling" process of a water droplet on a contaminated surface. The surface is tilted with an angle of $5^{\circ}$ to perform the rolling process. The water droplet has a volume of $8 \mu \mathrm{L}$ and provides a shear force to the contaminant ( $\mathrm{SiO}_{2}$ particle indicated by the white arrow). When the shear force is large enough to overcome the adhesive force between the contaminant and surface, the water droplet will lift the contaminant up from the surface. Figure $9(\mathrm{~b})$ is a schematic of the rolling cleaning process.

Figure $10(a)$ is a series of photos taken by a high speed camera, showing the "rebounding" process of a water droplet on a contaminated surface, which is tilted for $5^{\circ}$. $\mathrm{SiO}_{2}$ particles are indicated by white arrows. A water droplet with a volume of $8 \mu \mathrm{L}$ came out from a needle, spreading on the surface, collected the contaminant from the surface, and rebounded back to the air. Interestingly, the "rebounding" mode has a much higher cleaning efficiency than the rolling mode due to the large spreading area of the water droplet, which depends on the initial energy of the droplet and the status of the surface. Figure 10 (b) is a schematic of the "rebounding" process.

Figure 11(a) is the photos showing the contaminant absorbing process by a water droplet on a surface. Contaminants are sponge particles. A water droplet of $4 \mu \mathrm{L}$ is suspended on the tip of a needle. When it is close to the contaminant particle, the particle is absorbed into the droplet due to the high surface tension. The water droplet does not need to contact with the surface to make it clean, 


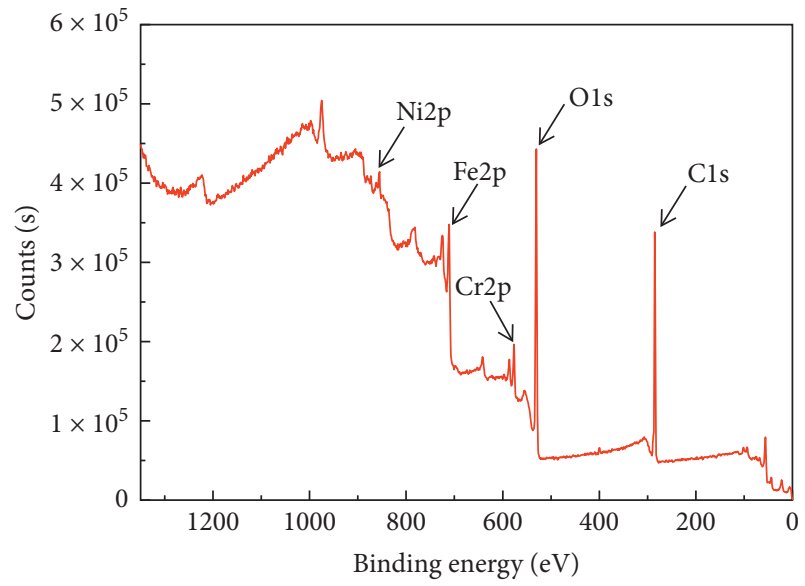

(a)

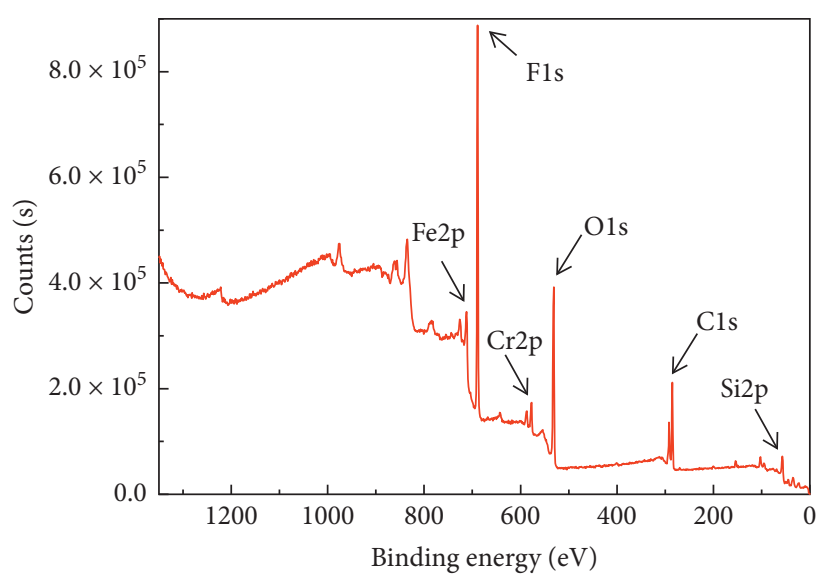

(b)

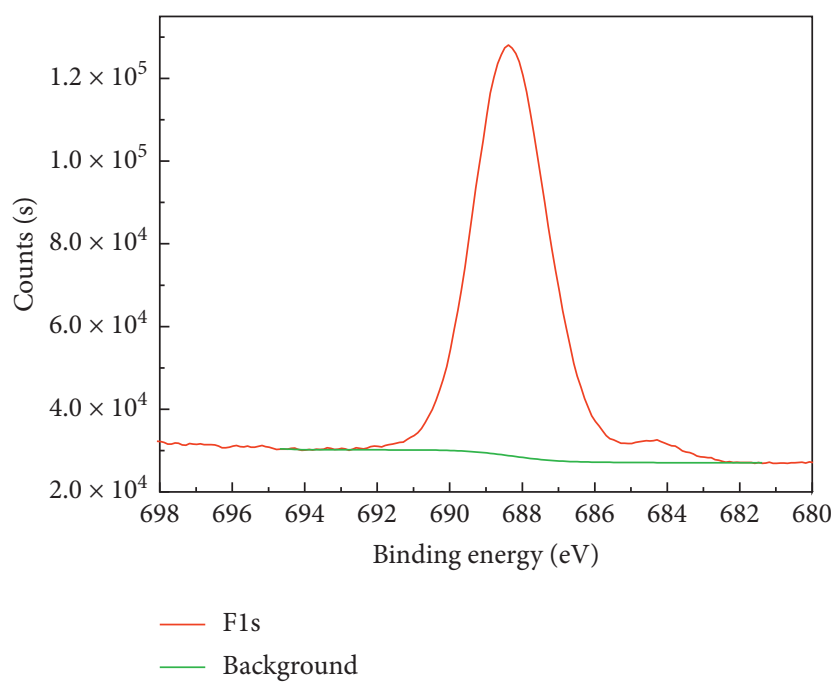

(c)

FIgURE 7: XPS diagrams of S1: (a) before fluorination, (b) after fluorination, and (c) F1s element.

TABLE 4: Surface elemental compositions and functional groups of S1 after fluorination (FS1).

\begin{tabular}{|c|c|c|c|}
\hline Element & Functional group & Binding energy $(\mathrm{eV})$ & Atomic (\%) \\
\hline \multirow{4}{*}{$\mathrm{C}_{1 \mathrm{~s}}$} & $\mathrm{C}-\mathrm{H}$ & 284.8 & 20.31 \\
\hline & $\mathrm{C}=\mathrm{O}, \mathrm{C}-\mathrm{F}$ & 287.8 & 2.29 \\
\hline & $\mathrm{C}-\mathrm{CO}_{3}, \mathrm{CF}_{2}$ & 290.8 & 7.96 \\
\hline & $\mathrm{CF}_{3}$ & 292.7 & 2.24 \\
\hline \multirow{2}{*}{$\mathrm{O}_{1 \mathrm{~s}}$} & $\mathrm{Cr}_{2} \mathrm{O}_{3}, \mathrm{CrO}_{3}, \mathrm{Fe}_{2} \mathrm{O}_{3}, \mathrm{Fe}_{3} \mathrm{O}_{4}, \mathrm{FeOOH}$ & 530.2 & 15.48 \\
\hline & $\mathrm{OH}$ & 531.8 & 10.31 \\
\hline \multirow[t]{2}{*}{$\mathrm{N}_{1 \mathrm{~s}}$} & $\mathrm{~N}_{2}, \mathrm{NH}_{3}$ & 400.0 & 0.62 \\
\hline & Metallic Fe & 719.9 & 0.60 \\
\hline \multirow[t]{2}{*}{$\mathrm{Fe}_{2 \mathrm{p}}$} & $\mathrm{Fe}^{3+}$ & 710.5 & 3.48 \\
\hline & $\mathrm{FeOOH}$ & 711.5 & 4.04 \\
\hline $\mathrm{Cr}_{2 \mathrm{p}}$ & $\mathrm{Cr}_{2} \mathrm{O}_{3}$ & 576.7 & 2.14 \\
\hline $\mathrm{F}_{1 \mathrm{~s}}$ & $\mathrm{CF}_{2}$ & 688.9 & 26.94 \\
\hline $\mathrm{Si}_{2 p}$ & $\mathrm{Si}-\mathrm{O}$ & 100.2 & 3.21 \\
\hline
\end{tabular}


(a)

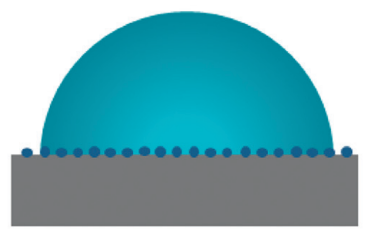

Fluorination

(d)

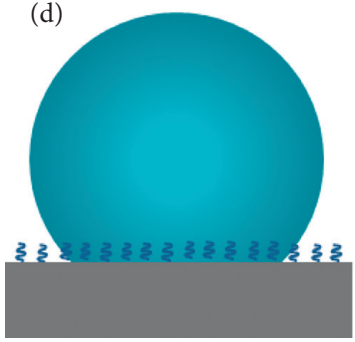

(b)
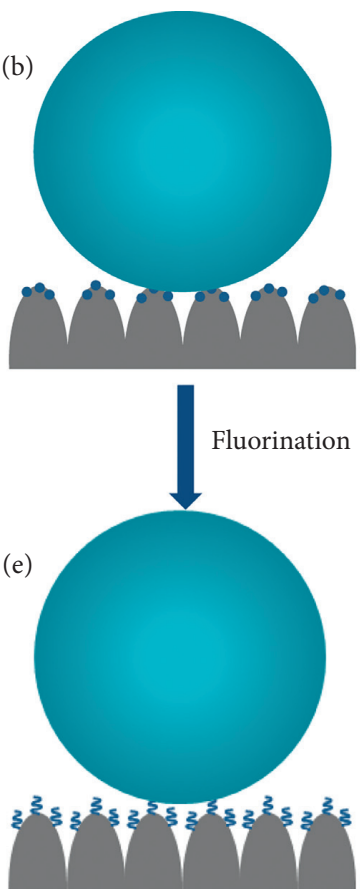

(c)
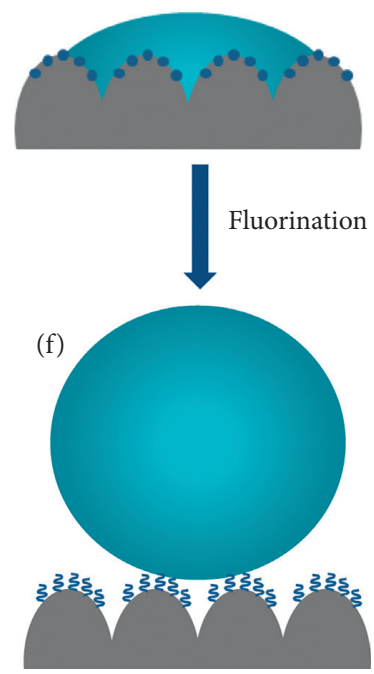

Figure 8: Wettability model of different specimens before and after fluorination. (a, d) SS, (b, e) S1, and (c, f) S6; •: metallic bonds or hydroxyl groups and ३ె: hydrophobic functional groups.
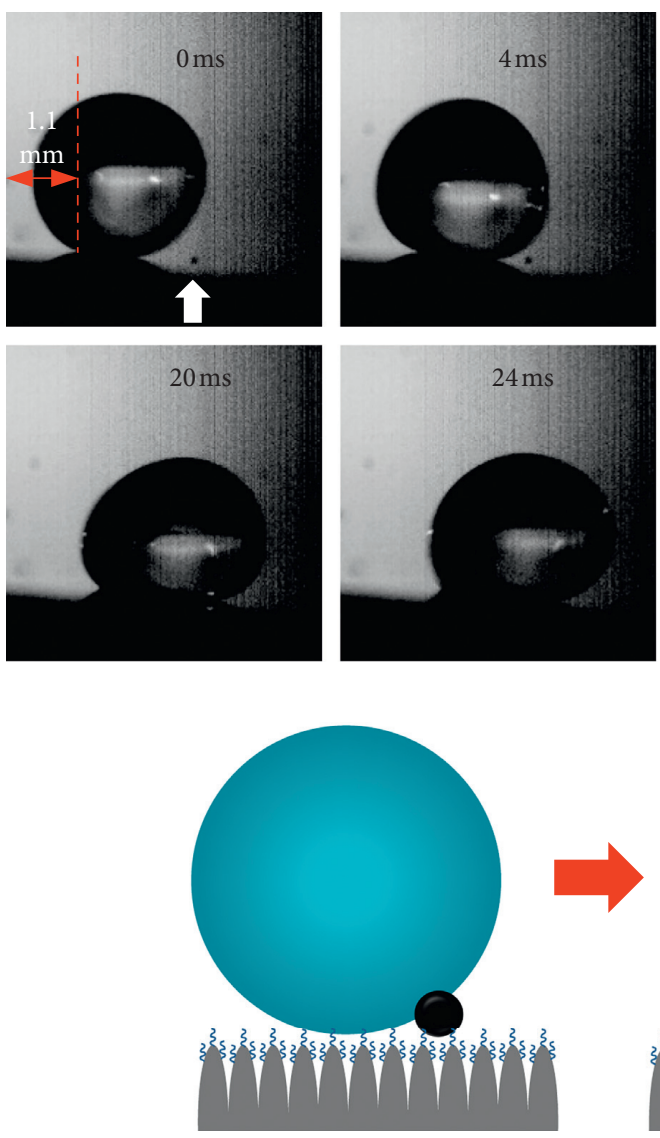
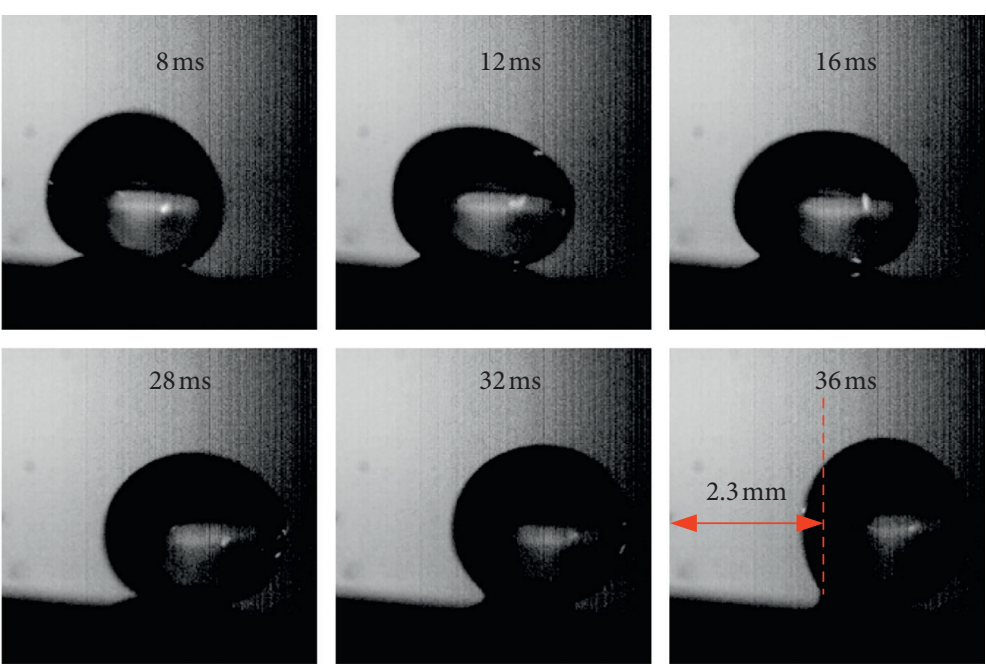

(a)
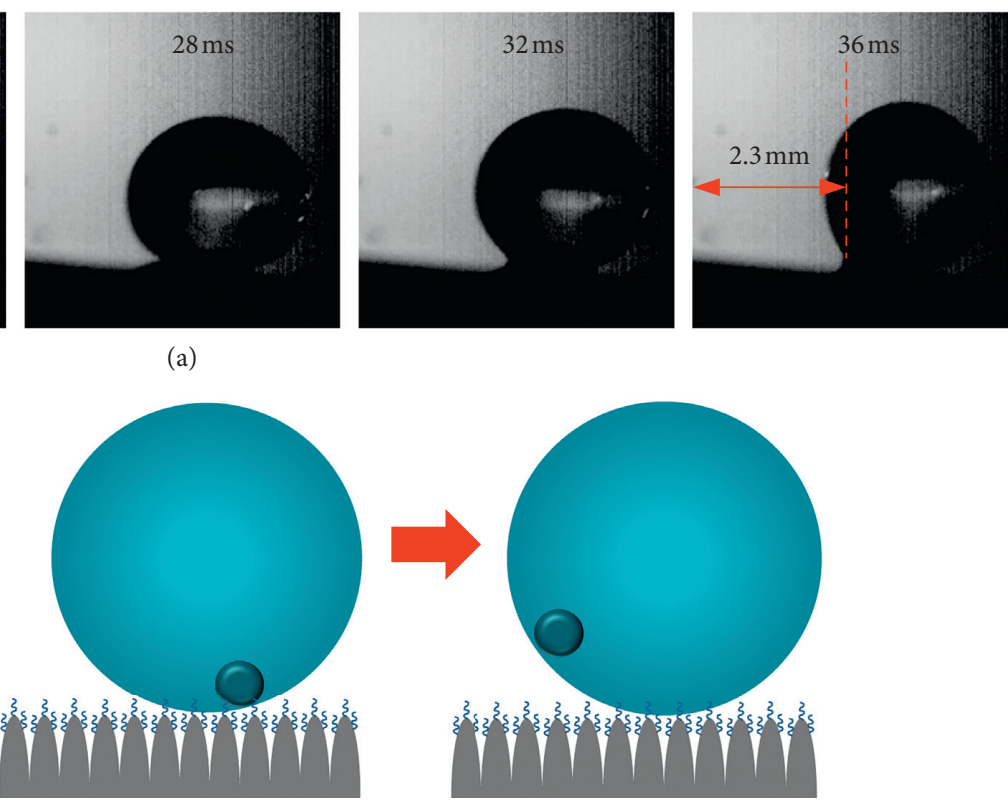

(b)

FIGURE 9: "Rolling" cleaning mode: (a) photos recorded by using a high speed camera and (b) schematic of antifouling process. 

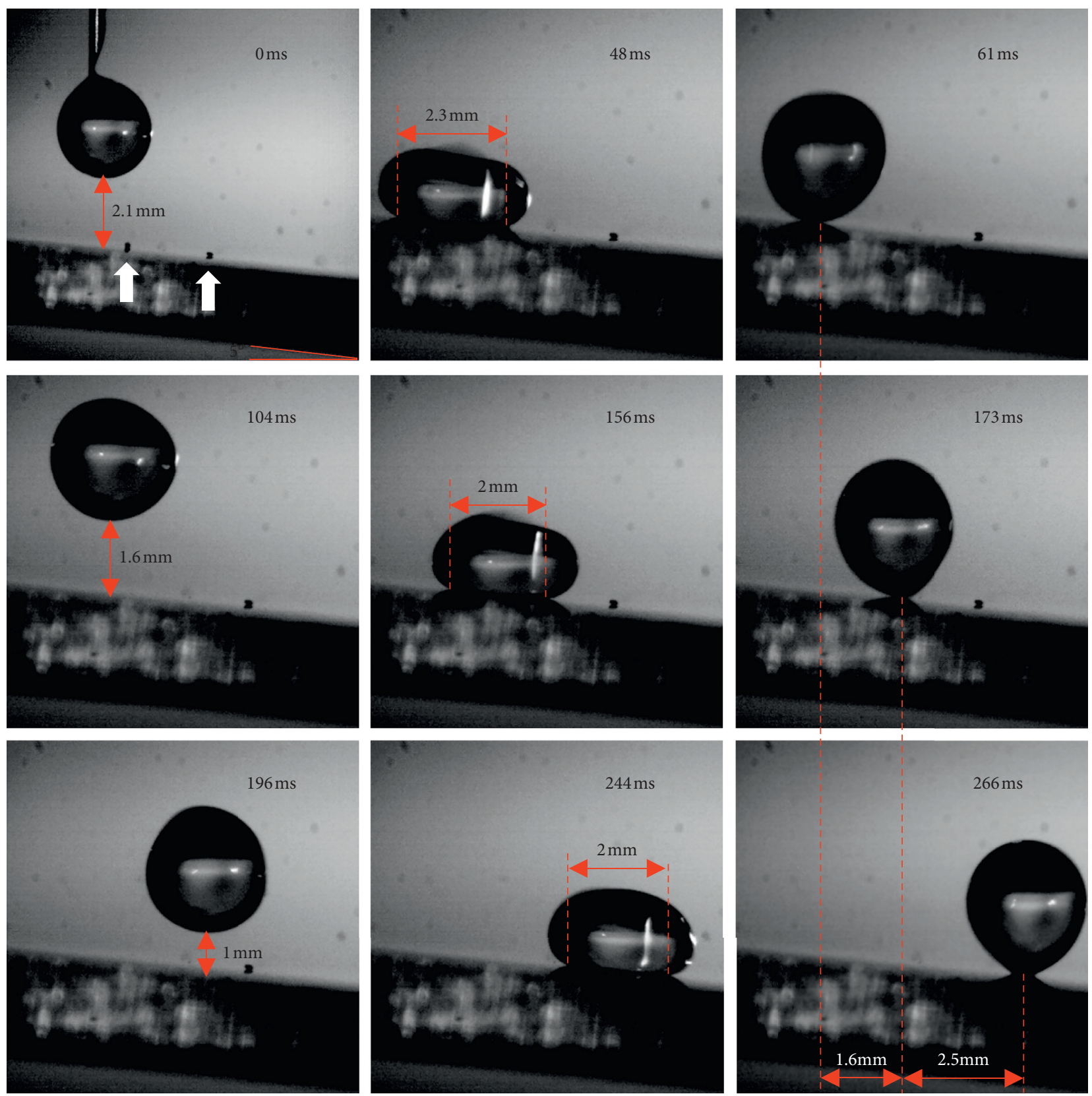

(a)
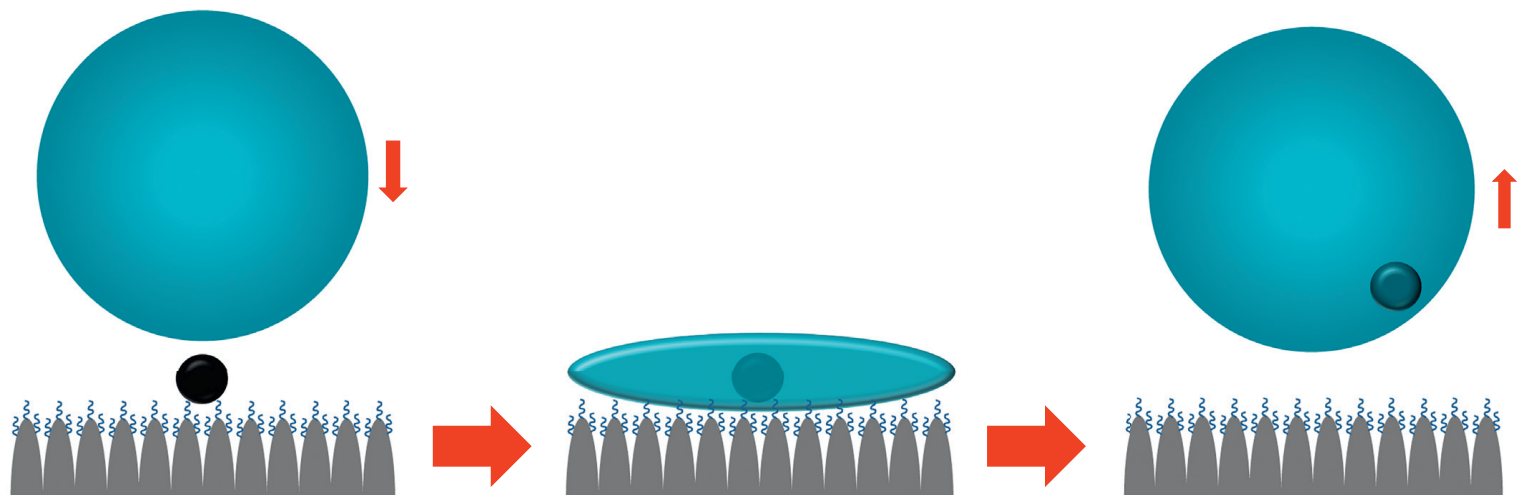

(b)

Figure 10: "Rebounding" cleaning mode: (a) high speed camera photos and (b) schematic of the particle removing process. 

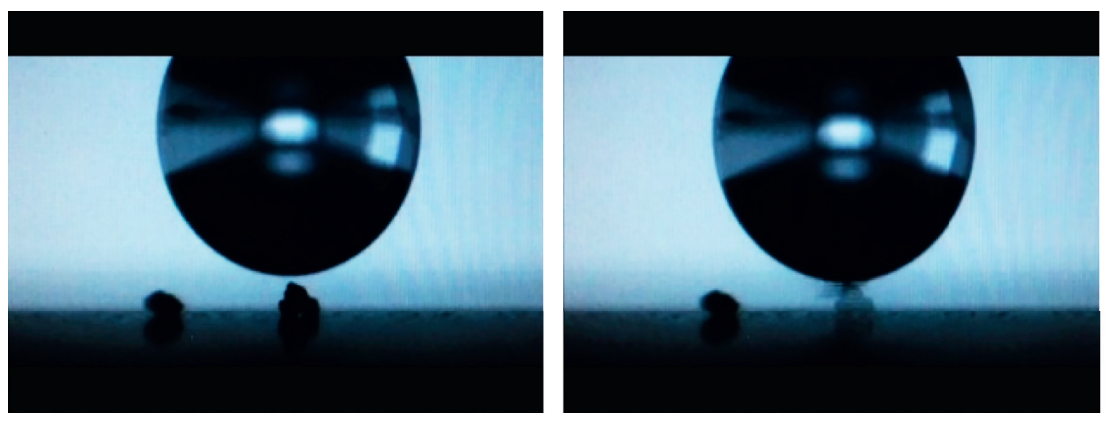

(a)
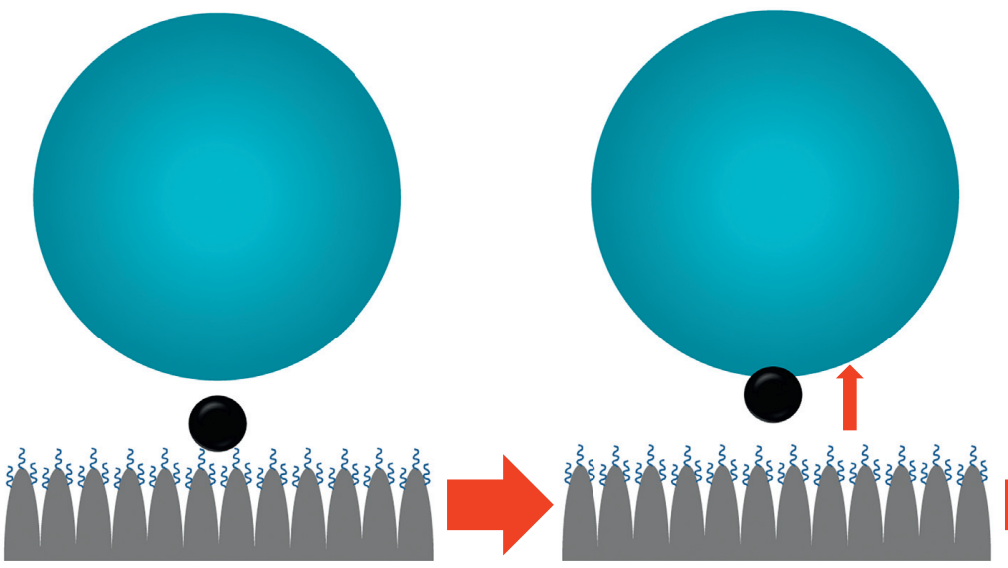

(b)
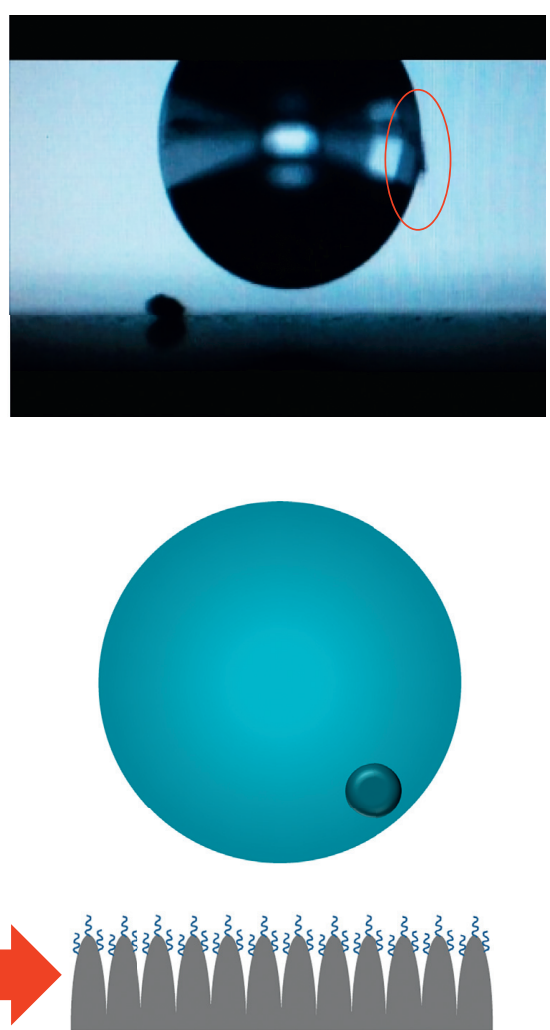

FIGURE 11: "Absorbing" cleaning mode: (a) photos taken by using a camera and (b) schematic of the "absorbing" particle removing process.

which can be regarded a damage-free cleaning process. Figure $11(\mathrm{~b})$ is a schematic of the "absorbing" cleaning mode.

\section{Conclusions}

This article presents techniques to make self-cleaning stainless steel (SS) surface, including tailoring surface morphology by femtosecond laser irradiation and reducing surface free energy by fluorination. Results revealed that different micro/nanostructures including laser-induced periodic structures and nodular structures were obtained on 304SS. Fluorine-free surfaces with controllable water contact angles (CAs) from hydrophilic to superhydrophobic were obtained by using one-step femtosecond laser scan, which are desirable for microfluidic devices, lab-on-a-chip, sensor, and microreactor applications. Surface free energies of laser irradiated surfaces vary significantly from $23.1 \pm 0.4 \mathrm{mN} / \mathrm{m}$ to $60.1 \pm 0.2 \mathrm{mN} / \mathrm{m}$ comparing to the untreated $304 \mathrm{SS}$ $(42.2 \pm 2.0 \mathrm{mN} / \mathrm{m})$; and the water contact angle roughly decreased with the increasing surface free energy. After fluorination treatment, the surface free energies of all specimens were reduced and CAs were much increased. All specimens showed near superhydrophobic property $\left(\mathrm{CA}=\sim 150^{\circ}\right)$ except for the fluorinated 304SS $\left(103^{\circ}\right)$. The adhesive property of laser irradiated surface was reduced due to the formation of surface hydrophobic functional groups such as $\mathrm{C}-\mathrm{F},-\mathrm{CF}_{2}$, and $-\mathrm{CF}_{3}$. A wettability model of specimens before and after fluorination was proposed, in which the influence of micro/nanostructures, fluorination, and their combined effects on CAs were analysed. The interaction behaviors between water droplets and different types of particulate pollutants on self-cleaning SS were monitored and recorded. Three particulate cleaning modes, rolling, rebounding, and absorbing modes, have been suggested.

\section{Data Availability}

The data used to support the findings of this study are included within the article.

\section{Conflicts of Interest}

The authors declare that there are no conflicts of interest regarding the publication of this paper.

\section{Acknowledgments}

This work was supported by the National Natural Science Foundation of China (NSFC) (Grant nos.: 51701087 and 51535003) and Special Foundation for Young Scientists of LFRC.

\section{References}

[1] M. Liu and L. Jiang, "Switchable adhesion on liquid/solid interfaces," Advanced Functional Materials, vol. 20, no. 21, pp. 3753-3764, 2010. 
[2] I. Sas, R. E. Gorga, J. A. Joines, and K. A. Thoney, "Literature review on superhydrophobic self-cleaning surfaces produced by electrospinning," Journal of Polymer Science Part B: Polymer Physics, vol. 50, no. 12, pp. 824-845, 2012.

[3] S. T. Yohe, J. D. Freedman, E. J. Falde, Y. L. Colson, and M. W. Grinstaff, "A mechanistic study of wetting superhydrophobic porous 3D meshes," Advanced Functional Materials, vol. 23, no. 29, pp. 3628-3637, 2013.

[4] J. Li, Z. Jing, F. Zha, Y. Yang, Q. Wang, and Z. Lei, "Facile spray-coating process for the fabrication of tunable adhesive superhydrophobic surfaces with heterogeneous chemical compositions used for selective transportation of microdroplets with different volumes," ACS Applied Materials \& Interfaces, vol. 6, no. 11, pp. 8868-8877, 2014.

[5] K. Efimenko, J. Finlay, M. E. Callow, J. A. Callow, and J. Genzer, "Development and testing of hierarchically wrinkled coatings for marine antifouling," ACS Applied Materials \& Interfaces, vol. 1, no. 5, pp. 1031-1040, 2009.

[6] X. Yao, L. Xu, and L. Jiang, "Fabrication and characterization of superhydrophobic surfaces with dynamic stability," Advanced Functional Materials, vol. 20, no. 19, pp. 3343-3349, 2010.

[7] D. Zhang, F. Chen, Q. Yang et al., "A simple way to achieve pattern-dependent tunable adhesion in superhydrophobic surfaces by a femtosecond laser," ACS Applied Materials \& Interfaces, vol. 4, no. 9, pp. 4905-4912, 2012.

[8] W. Wang, Y. Q. Liu, Y. Liu et al., "Direct laser writing of superhydrophobic pdms elastomers for controllable manipulation via marangoni effect," Advanced Functional Materials, vol. 27, 2017.

[9] A. Y. Vorobyev and C. Guo, "Multifunctional surfaces produced by femtosecond laser pulses," Journal of Applied Physics, vol. 117, p. 033103, 2015.

[10] G. Li, J. Li, C. Zhang et al., "Large-area one-step assembly of three-dimensional porous metal micro/nanocages by ethanolassisted femtosecond laser irradiation for enhanced antireflection and hydrophobicity," ACS Applied Materials \& Interfaces, vol. 7, no. 1, pp. 383-390, 2015.

[11] I. Jun, Y. W. Chung, Y. H. Heo et al., "Creating hierarchical topographies on fibrous platforms using femtosecond laser ablation for directing myoblasts behavior," ACS Applied Materials \& Interfaces, vol. 8, 2016.

[12] T. N. Banuprasad, T. V. Vinay, K. S. Cherumannil, S. Varghese, S. D. George, and S. N. Varanakkottu, "Fast transport of water droplets over a thermo-switchable surface using rewritable wettability gradient," ACS Applied Materials \& Interfaces, vol. 9, 2017.

[13] J. Yong, F. Chen, Q. Yang et al., "Rapid fabrication of largearea concave microlens arrays on PDMS by a femtosecond laser," ACS Applied Materials \& Interfaces, vol. 5, no. 19, pp. 9382-9385, 2013.

[14] C. De Marco, S. M. Eaton, R. Suriano et al., "Surface properties of femtosecond laser ablated PMMA," ACS Applied Materials \& Interfaces, vol. 2, no. 8, pp. 2377-2384, 2010.

[15] J. Yong, F. Chen, J. Huo et al., "Femtosecond laser induced underwater superaerophilic and superaerophobic PDMS sheets with through microholes for selective passage of air bubbles and further collection of underwater gas," Nanoscale, vol. 10, no. 8, pp. 3688-3696, 2018.

[16] S. Moradi, N. Hadjesfandiari, S. F. Toosi, J. N. Kizhakkedathu, and S. G. Hatzikiriakos, "Effect of extreme wettability on platelet adhesion on metallic implants: from superhydrophilicity to superhydrophobicity," ACS Applied Materials \& Interfaces, vol. 8, no. 27, pp. 17631-17641, 2016.
[17] J. Long, P. Fan, D. Gong et al., "Superhydrophobic surfaces fabricated by femtosecond laser with tunable water adhesion: from Lotus leaf to rose petal," ACS Applied Materials \& Interfaces, vol. 7, no. 18, pp. 9858-9865, 2015.

[18] S. Zouaghi, T. Six, S. Bellayer et al., "Antifouling biomimetic liquid-infused stainless steel: application to dairy industrial processing," Acs Applied Materials \& Interfaces, vol. 9, 2017.

[19] S. Schlie-Wolter, A. Deiwick, E. Fadeeva, G. Paasche, T. Lenarz, and B. N. Chichkov, "Topography and coating of platinum improve the electrochemical properties and neuronal guidance," ACS Applied Materials \& Interfaces, vol. 5, no. 3, pp. 1070-1077, 2013.

[20] Y. Li, D. X. Luong, J. Zhang et al., "Laser-induced graphene in controlled atmospheres: from superhydrophilic to superhydrophobic surfaces," Advanced Materials, vol. 29, 2017.

[21] K. Yin, D. Chu, X. Dong, C. Wang, J.-A. Duan, and J. He, "Femtosecond laser induced robust periodic nanoripple structured mesh for highly efficient oil-water separation," Nanoscale, vol. 9, no. 37, pp. 14229-14235, 2017.

[22] H. Shi, Z. Cui, W. Wang, B. Xu, D. Gong, and W. Zhang, "Blackening of magnesium alloy using femtosecond laser," Applied Optics, vol. 54, no. 25, pp. 7766-7772, 2015.

[23] M. S. Ahsan and M. S. Lee, "Colorizing mechanism of brass surface by femtosecond laser induced microstructures," Optik International Journal for Light and Electron Optics, vol. 124, no. 18 , pp. 3631-3635, 2013.

[24] T. Y. Hwang, A. Y. Vorobyev, and C. Guo, "Ultrafast dynamics of femtosecond laser-induced nanostructure formation on metals," Applied Physics Letters, vol. 95, no. 12, pp. 123111-123113, 2009.

[25] A. Y. Vorobyev and C. Guo, "Direct femtosecond laser surface nano/microstructuring and its applications," Laser \& Photonics Reviews, vol. 7, no. 3, pp. 385-407, 2013.

[26] F. Chen, D. Zhang, Q. Yang et al., "Bioinspired wetting surface via laser microfabrication," ACS Applied Materials \& Interfaces, vol. 5, no. 15, pp. 6777-6792, 2013.

[27] C. Yao, S. Xu, Y. Ye et al., “The influence of femtosecond laser repetition rates and pulse numbers on the formation of micro/ nano structures on stainless steel," Journal of Alloys and Compounds, vol. 722, pp. 235-241, 2017.

[28] L. Li, V. Breedveld, and D. W. Hess, "Creation of superhydrophobic stainless steel surfaces by acid treatments and hydrophobic film deposition," ACS Applied Materials \& Interfaces, vol. 4, no. 9, pp. 4549-4556, 2012.

[29] K. M. T. Ahmmed, E. J. Y. Ling, P. Servio, and A.-M. Kietzig, "Introducing a new optimization tool for femtosecond laserinduced surface texturing on titanium, stainless steel, aluminum and copper," Optics and Lasers in Engineering, vol. 66, pp. 258-268, 2015.

[30] V. Oliveira, S. Ausset, and R. Vilar, "Surface micro/nanostructuring of titanium under stationary and non-stationary femtosecond laser irradiation," Applied Surface Science, vol. 255, no. 17, pp. 7556-7560, 2009.

[31] Y. Zhang, L. Wang, and J. Gong, "Numerical simulation of femtosecond laser multi-pulse ablation of Ni-Ti alloy," Acta Photonica Sinica, vol. 45, p. 0514002, 2016.

[32] W. Pfleging, R. Kumari, H. Besser, T. Scharnweber, and J. D. Majumdar, "Laser surface textured titanium alloy (Ti6Al-4V): Part 1-surface characterization," Applied Surface Science, vol. 355, pp. 104-111, 2015.

[33] L. Feng, S. Li, Y. Li et al., "Super-hydrophobic surfaces: from natural to artificial," Advanced Materials, vol. 14, no. 24, pp. 1857-1860, 2002. 
[34] B.-j. Li, M. Zhou, W. Zhang, G. Amoako, and C.-y. Gao, "Comparison of structures and hydrophobicity of femtosecond and nanosecond laser-etched surfaces on silicon," Applied Surface Science, vol. 263, pp. 45-49, 2012.

[35] A. Steele, B. K. Nayak, A. Davis, M. C. Gupta, and E. Loth, "Linear abrasion of a titanium superhydrophobic surface prepared by ultrafast laser microtexturing," Journal of Micromechanics and Microengineering, vol. 23, no. 11, p. 115012, 2013.

[36] L. Yao and J. He, "Recent progress in antireflection and selfcleaning technology-from surface engineering to functional surfaces," Progress in Materials Science, vol. 61, pp. 94-143, 2014.

[37] B.-j. Li, H. Li, L.-j. Huang, N.-f. Ren, and X. Kong, "Femtosecond pulsed laser textured titanium surfaces with stable superhydrophilicity and superhydrophobicity," Applied Surface Science, vol. 389, pp. 585-593, 2016. 